\title{
Synthesis and Electrochemical Characterisation of Novel Hybrid Copper / Poly (diphenylamine) (PDPA) Nanocomposites
}

\section{S. Ramalingam}

\begin{abstract}
The Poly (diphenylamine) (PDPA) nanoparticles was synthesized by surfactant assisted dilute polymerization method and characterized by UV-Visible, FTIR and Cyclic Voltammetry techniques. The PDPA nanoparticles were then suspended in an acidified copper sulphate electrolytic bath to prepare Cu-PDPA nanocomposites by simple electrodeposition technique. The XRD analysis revealed that the crystallite structure of Cu-PDPA nanocomposites and pure copper coatings was crystalline fcc and the grain size was $32 \mathrm{~nm}$ for pure $\mathrm{Cu}$ and 27 nm for Cu-PDPA nanocomposites. This decrease in crystallite size of Cu-PDPA nanocomposites shows the inclusion of PDPA nanoparticles was uniformly distributed throughout the copper matrix. The microstructure of the Cu-PDPA nanocomposites was examined by SEM analysis shows cauliflower like crystallites with layer by layer outward growth compared to electrodeposited pure copper coatings. The Electrochemical AC impedance and Tafel polarization studies were performed for electrodeposited copper and Cu-PDPA nanocomposites in $3.5 \%$ $\mathrm{NaCl}$ solution. It revealed that the $\mathrm{Cu}-\mathrm{PDPA}$ nanocomposite coatings were found to be more corrosion resistance than electrodeposited pure copper coating.
\end{abstract}

Keywords: Cu-PDPA Nanocomposites, Poly (diphenylamine) (PDPA) nanoparticles, Electrodeposition, Corrosion resistance.

\section{INTRODUCTION}

In the recent years, there are numerous research works are concerted on developing metal matrix nanocomposite (MMNC) coatings with particulates, fibers and polymers as second phase reinforcement materials because of their exceptional mechanical, tribological and anti-corrosion properties and their potential engineering applications. Some of the characteristic features of these nanocomposite coatings are improved wear resistance, corrosion resistance, micro hardness and strength compared to pure metals or alloys [1-12]. Particularly, the development of novel metal / polymer nanocomposites has received considerable attention because of its variety of engineering applications. The polyaniline group of conducting polymeric materials has received ample attention because of its simple method of preparation and their electrical, electrochemical and optical properties. Furthermore, the poly (diphenylamine) (PDPA) is

Revised Manuscript Received on December 05, 2019.

* Correspondence Author

S. Ramalingam*, Department of Chemistry, School of Advanced Sciences, Kalasalingam Academy of Research and Education (Deemed to be University), Krishnankoil-626 126. Tamil Nadu, India.

Email: rama.s.lingam@gmail.com. found to be a suitable material for the composite material preparation due to their characteristic properties different from polyaniline (PANI) [13-21].

In the present study, our aim is to prepare a noval hybrid metal / polymer nanocomposite material of Cu-Poly (diphenylamine) (PDPA) nanocomposites by simple and low cost electrodeposition method and the prepared nanocomposites are to be characterized for its mechanical and anticorrosive properties. The electrodeposition technique is an exceptional method for the synthesis of metals, alloys, metal matrix nanocomposites and metal-polymer nanocomposite coatings etc. [1][3][6][9][17]. The advantage of the electrodeposition technique is simple, low temperature technique with industrial applicability.

The objectives of the present work is, (i) To prepare Poly (diphenylamine) polymer by surfactant assisted dilute polymerization method and to characterize the polymer by UV-Visible, FTIR and Cyclic Voltammetry techniques. (ii) To prepare $\mathrm{Cu}$-Poly(diphenylamine) nanocomposites by electrodeposition technique, by suspending the poly (diphenylamine) nanoparticles in the acid copper electrolytic bath and to characterize the Cu-PDPA nanocomposites and pure copper by XRD, SEM, EIS and Tafel polarization techniques to study the structure, microstructure and corrosion resistance properties.

\section{EXPERIMENTAL}

\section{A. Synthesis of Poly (diphenylamine) (PDPA) Nanoparticles}

To the stirring solution of $0.1 \mathrm{M}$ diphenylamine monomer in water, 4M sulphuric acid is added to till the complete dissolution of DPA monomer. After the complete dissolution of DPA monomer, $0.005 \mathrm{M}$ concentration of surfactant CTAB (cetyltrimethylammonium bromide) is mixed with it and the freshly prepared $0.4 \mathrm{M}$ solution of ammonium persulphate is added in drop wise manner to the stirring solution for the duration of $2 \mathrm{hrs}$. A dark green colored product of poly (diphenylamine) (PDPA) polymer thus obtained is filtered and washed with water and dried [22-25].

\section{B. Preparation of Cu-Polydiphenylamine (PDPA) Nanocomposites}

The Cu-PDPA nanocomposite was prepared by suspending the poly (diphenylamine) nanoparticles in an acidified 
copper sulphate bath by DC electrodeposition method. The bath composition for the electrodeposition of Copper and $\mathrm{Cu}-\mathrm{PDPA}$ nanocomposites was $\mathrm{CuSO}_{4} \cdot 5 \mathrm{H}_{2} \mathrm{O}(0.3 \mathrm{M})$ and $\mathrm{H}_{2} \mathrm{SO}_{4} \quad(1.3 \mathrm{M})$. The concentrations of the poly(diphenylamine) (PDPA) nanoparticles in various baths are $1 \mathrm{~g} / \mathrm{l}, 3 \mathrm{~g} / \mathrm{l}, 5 \mathrm{~g} / \mathrm{l}$ and $10 \mathrm{~g} / \mathrm{l}$. Stirring was applied in each bath during the electrodeposition process to enhance the uniform deposition of PDPA nanoparticles. The $\mathrm{Cu}$-PDPA nanocomposite coatings of $\sim 60 \mu \mathrm{m}$ in thickness were deposited on the copper substrate (cathode) of $4.0 \mathrm{~cm}^{2}$ surface area. A pure copper bar was used as the anode material for deposition process. The gelatin was used $(1.0 \mathrm{~g} / \mathrm{l})$ as additive in the electroplating bath solution to get smooth, pore-free and fine grained deposits. The electroplating was carried out by the applied current density of $5.0 \mathrm{~A} / \mathrm{dm}^{2}$ with the $\mathrm{pH}$ of $\sim 1$ at room temperature $\left(\sim 30^{\circ} \mathrm{C}\right)$. The electrodeposited pure copper coatings (without PDPA nanoparticles) were also obtained under the same conditions from the acid copper sulphate bath at $30^{\circ} \mathrm{C}[1][3][6][9][17]$.

\section{Results AND Discussions}

The Poly (diphenylamine) (PDPA) was synthesized by surfactant assisted dilute polymerization method and it was characterized by spectroscopic and cyclic voltammetric techniques.

\section{A. Characterization of Poly (diphenylamine) (PDPA) Polymer}

\section{UV-Visible Spectral Studies}

The UV-Visible absorption spectrum for the synthesized poly (diphenylamine) (PDPA) polymer was taken by Shimadzu UVPC-2401 UV-Visible spectrophotometer is shown in Fig. 1. In the UV-Visible spectrum (Fig. 1), the presence of absorption peak at $337 \mathrm{~nm}$ corresponds to the $\pi-\pi^{*}$ transition in the benzenoid ring.

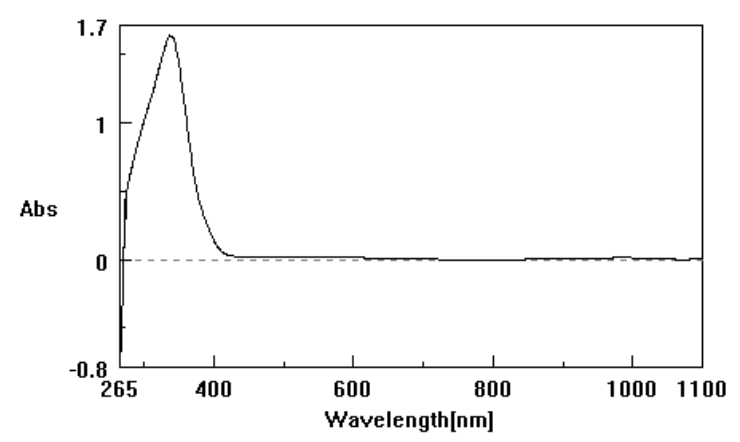

Fig. 1. UV-Visible spectrum for poly(diphenylamine) (PDPA) polymer.

\section{FTIR Analysis}

The FTIR spectrum of Poly (diphenylamine) was taken with $\mathrm{KBr}$ pellets using Perkin Elmer FTIR spectrophotometer (Fig. 2). A small peak at $3385 \mathrm{~cm}^{-1}$ indicates the N-H stretching vibration mode. The bands at $1596 \mathrm{~cm}^{-1}$ and 1646 $\mathrm{cm}^{-1}$ were assigned to $\mathrm{N}-\mathrm{H}$ bending of $1^{\circ}$ amines. The band at $1316 \mathrm{~cm}^{-1}$ is due to $\mathrm{C}-\mathrm{N}$ stretching vibration of aromatic amine. A small peak observed at $747 \mathrm{~cm}^{-1}$ shows the presence of phenyl groups.

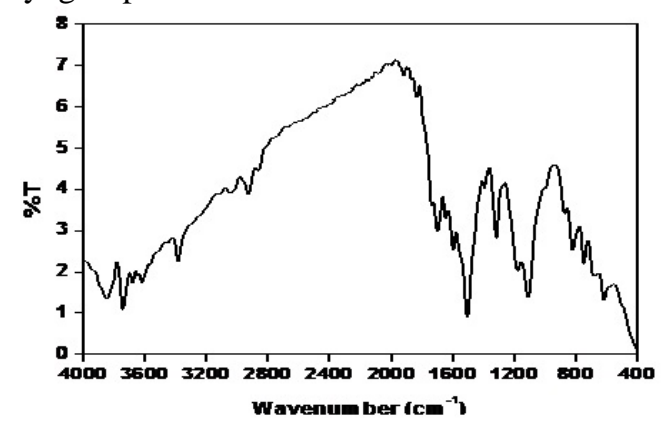

Fig. 2. FTIR Spectrum of Poly (diphenylamine) (PDPA) polymer.

\section{Cyclic Voltammetry Studies}

The cyclic voltammogram of poly (diphenylamine) (PDPA) polymer was recorded by using BAS $100 \mathrm{~W}$ electrochemical analyzer. The cyclic voltammogram of poly (diphenylamine) was recorded by scanning the potential between 0 and $+1.3 \mathrm{~V}$ at a sweep rate of $100 \mathrm{mV} / \mathrm{s}$ using the dip coated electrode in the background electrolyte of $0.1 \mathrm{M} \mathrm{H}_{2} \mathrm{SO}_{4}$. Two peaks are found in the anodic side centered on $0.57 \mathrm{~V}$ and $0.78 \mathrm{~V}$. The oxidation peaks may be due to the oxidation of the amine moiety present in the polymeric backbone. In addition, a cathodic peak is obtained around $0.46 \mathrm{~V}$ representing the subsequent reduction of the oxidized species. The electrochemical response recorded for the synthesized polymer is well in accordance with the literature reports (Fig. $3)$.

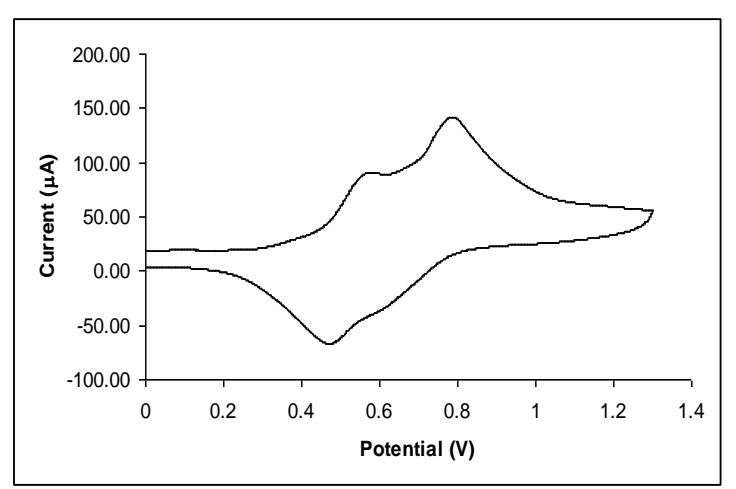

Fig. 3. Cyclic Voltammogram for Poly (diphenylamine) (PDPA) polymer.

\section{B. Characterization of Cu-PDPA Nanocomposites}

\section{XRD Analysis}

The XRD patterns for the electrodeposits of copper and Cu-PDPA nanocomposites are shown in Fig. 4(a \& b). By using the Debye-Scherrer formula the average grain size was measured and it was $\sim 32 \mathrm{~nm}$ for $\mathrm{Cu}$ and $\sim 27 \mathrm{~nm}$ for $\mathrm{Cu}$-PDPA nanocomposite coatings. Both the samples of pure $\mathrm{Cu}$ and $\mathrm{Cu}$-PDPA nanocomposites, shows the structure of crystalline fcc (face-centered cubic) and the preferred orientation of (111) plane, which is matched and confirmed from the JCPDS 
reference. This decrease in the average grain size of $\mathrm{Cu}$-PDPA nanocomposites shows the enhanced mechanical and anti-corrosion properties.

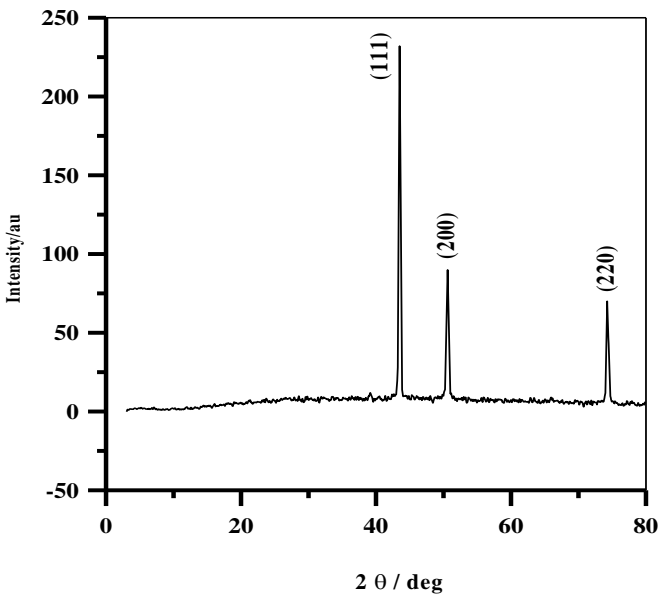

Fig. 4(a).

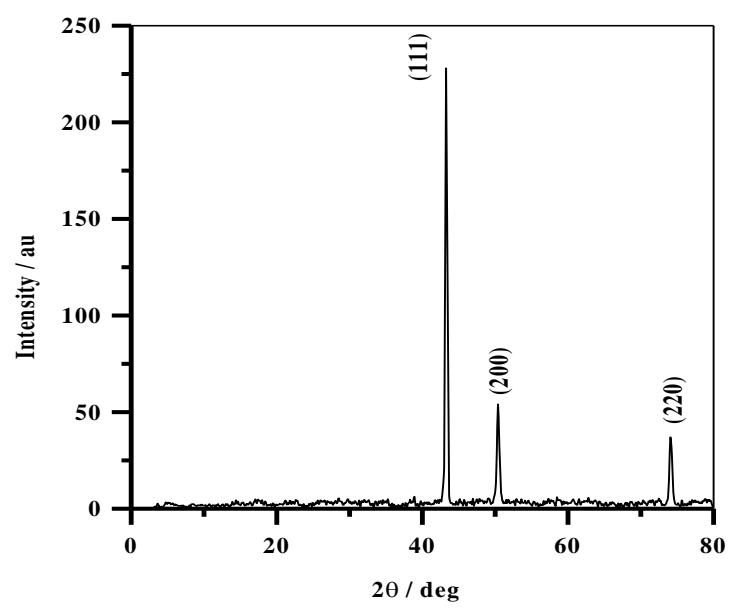

Fig. 4(b).

Fig. 4. XRD Patterns of electrodeposits (a) Pure Cu, (b) Cu-PDPA (5 g/l) nanocomposite.

\section{Corrosion Resistance Measurements}

\subsection{Electrochemical AC Impedance Spectroscopy (EIS) Analysis}

The anti-corrosion property of the $\mathrm{Cu}$-PDPA nanocomposites and pure copper electrodeposits were tested in electrochemical impedance spectroscopy (EIS) and Tafel polarization techniques using a three electrode cell setup. The electrodeposited samples of $1.0 \mathrm{~cm}^{2}$ area was used as the working electrode, the saturated calomel electrode (SCE) was used as reference electrode and the platinum wire is used as auxiliary electrode. These three electrodes are immersed in $3.5 \% \mathrm{NaCl}$ solution to record the Nyquist plot. From the Nyquist plots (Fig. 5(a\&b)), the charge transfer resistance $\left(\mathrm{R}_{\mathrm{ct}}\right)$ and the double layer capacitance $\left(\mathrm{C}_{\mathrm{dl}}\right)$ values are measured and are presented in the Table 1 . The charge transfer resistance $\left(\mathrm{R}_{\mathrm{ct}}\right)$ values for $\mathrm{Cu}$-PDPA nanocomposite coating was increased with increasing PDPA nanoparticles content in the $\mathrm{Cu}$-PDPA nanocomposites and the double layer capacitance $\left(\mathrm{C}_{\mathrm{dl}}\right)$ values was decreased compared to electrodeposited pure copper coatings (Table 1). It revealed that $\mathrm{Cu}-\mathrm{PDPA}$ nanocomposite coatings were more corrosion resistance than the electrodeposited pure copper in 3.5\% $\mathrm{NaCl}$ solution (Fig. 5(a\&b)).

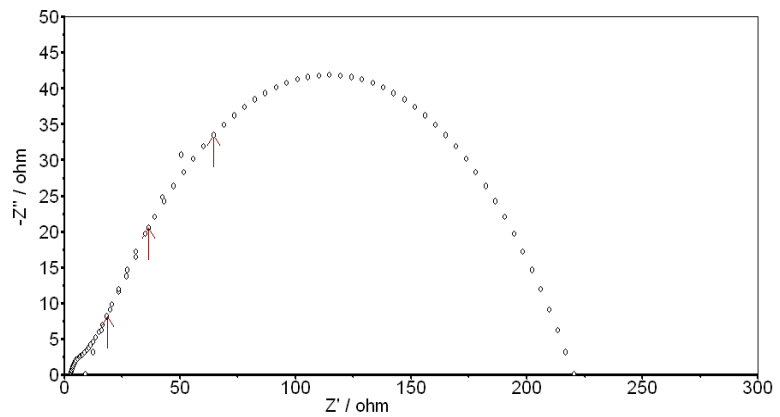

Fig. 5(a)

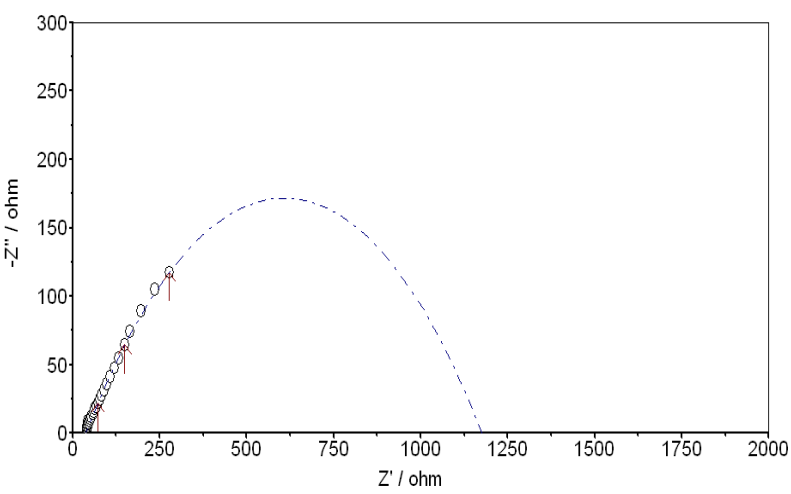

Fig. 5(b)

Fig. 5(a\&b). Nyquist plots for the electrodeposits (a) Copper (b) Cu-PDPA (10 g/l) Nanocomposite.

Table 1. Impedance parameters derived from the Nyquist plots for the electrodeposits of Copper and $\mathrm{Cu}-\mathrm{PDPA}$ nanocomposites.

\begin{tabular}{|l|l|l|l|}
\hline $\begin{array}{l}\text { Electrodeposit } \\
\mathbf{S}\end{array}$ & $\begin{array}{l}\text { PDPA } \\
\text { content in } \\
\mathbf{g p l}\end{array}$ & $\begin{array}{l}\mathbf{R}_{\mathbf{c t}} \\
\left(\boldsymbol{\Omega} / \mathbf{c m}^{2}\right)\end{array}$ & $\begin{array}{l}\mathbf{C}_{\mathbf{d l}} \\
\left(\boldsymbol{\mu} \mathbf{F} / \mathbf{c m}^{2}\right)\end{array}$ \\
\hline Copper & 0 & 220 & 53.07 \\
\hline $\begin{array}{l}\text { Cu-PDPA } \\
\text { nanocomposite }\end{array}$ & 1 & 540 & 31.22 \\
\hline $\begin{array}{l}\text { Cu-PDPA } \\
\text { nanocomposite }\end{array}$ & 3 & 650 & 26.53 \\
\hline $\begin{array}{l}\text { Cu-PDPA } \\
\text { nanocomposite }\end{array}$ & 5 & 950 & 22.74 \\
\hline $\begin{array}{l}\text { Cu-PDPA } \\
\text { nanocomposite }\end{array}$ & 10 & 1200 & 12.24 \\
\hline
\end{tabular}

\subsection{Tafel Polarization Studies}

The corrosion potential $\left(\mathrm{E}_{\text {corr }}\right)$, the corrosion current $\left({ }_{\text {corr }}^{\mathrm{i}}\right)$, tafel slopes $b_{a} \& b_{c}$ and the corrosion rate for the electrodeposited pure copper and Cu-PDPA nanocomposites were measured from the Tafel polarization curves (Fig. 6) and the results are presented in Table 2. 
The corrosion current $\left({ }_{\text {corr }}^{\mathrm{i}}\right)$ was decreased for all the $\mathrm{Cu}$-PDPA nanocomposite coatings compared to electrodeposited pure copper. The corrosion rate was decreased gradually for all the Cu-PDPA nanocomposites compared to electrodeposited pure copper.

It indicates that the $\mathrm{Cu}$-PDPA nanocomposites were more corrosion resistance than the electrodeposited pure copper in $3.5 \% \mathrm{NaCl}$ solution (Table 2).

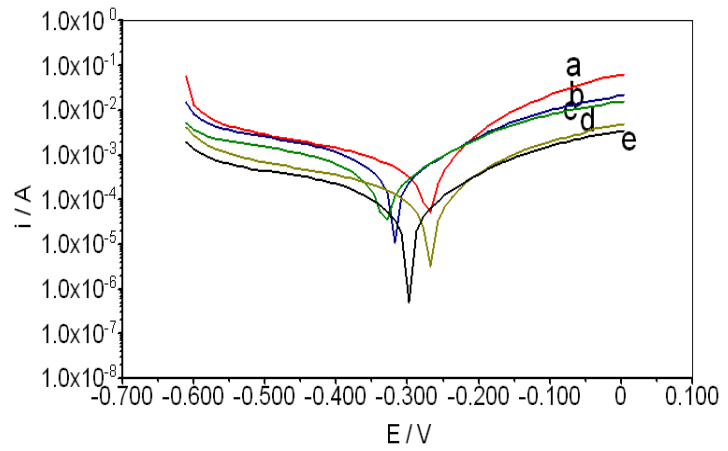

Fig. 6. Tafel plots for the electrodeposits (a) Copper, (b) Cu-PDPA (1 g/l), (c) Cu-PDPA (3 g/l), (d) Cu-PDPA (5 g/l), (e) Cu-PDPA (10 g/l) nanocomposites.

Table 2. Tafel parameters for the electrodeposits of Copper and Cu-PDPA nanocomposites.

\begin{tabular}{|l|c|l|l|c|}
\hline $\begin{array}{l}\text { Electrodeposit } \\
\mathbf{s}\end{array}$ & $\begin{array}{l}\text { PDPA } \\
\text { conten } \\
\mathbf{t} \\
\text { in gpl }\end{array}$ & $\begin{array}{l}\mathbf{E}_{\text {corr }} \\
(\mathbf{V}) \\
\mathbf{v s ~ S C E}\end{array}$ & $\begin{array}{l}\mathbf{i}_{\text {corr }} \\
\left(\boldsymbol{\mu A} / \mathbf{c m}^{2}\right. \\
)\end{array}$ & $\begin{array}{l}\text { Corrosion } \\
\text { rate / mm } \\
\text { year }^{-1}\end{array}$ \\
\hline Pure $\mathrm{Cu}$ & 0 & -0.269 & 101.6 & 1.178 \\
\hline $\begin{array}{l}\text { Cu-PDPA } \\
\text { nanocomposite }\end{array}$ & 1 & -0.332 & 88.79 & 1.029 \\
\hline $\begin{array}{l}\text { Cu-PDPA } \\
\text { nanocomposite }\end{array}$ & 3 & -0.318 & 20.14 & 0.2335 \\
\hline $\begin{array}{l}\text { Cu-PDPA } \\
\text { nanocomposite }\end{array}$ & 5 & -0.285 & 7.45 & 0.0863 \\
\hline $\begin{array}{l}\text { Cu-PDPA } \\
\text { nanocomposite }\end{array}$ & 10 & -0.270 & 2.22 & 0.0257 \\
\hline
\end{tabular}

\section{Scanning Electron Microscopy (SEM) Analysis}

The microstructure of the Cu-PDPA nanocomposites and copper electrodeposits was examined by SEM analysis is shown in Fig. 7(a \& b).

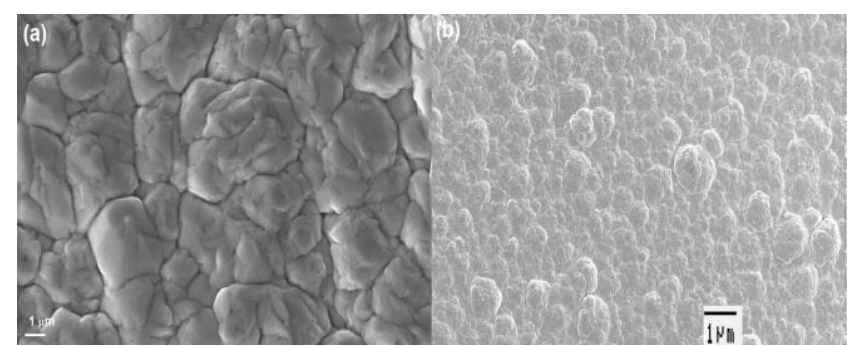

Fig. 7. SEM images of electrodeposits (a) Pure $\mathrm{Cu}$, (b) Cu-PDPA nanocomposites.

The Pure copper (Fig. 7(a)) shows smooth surface with uniform copper crystallites compared to $\mathrm{Cu}-\mathrm{PDPA}$ nanocomposites (Fig. 7(b)). The Cu-PDPA nanocomposite shows uniform distribution of poly (diphenylamine) (PDPA) nanoparticles with cauliflower like crystallites with layer by layer outward growth on the copper matrix (Fig. 7(b)).

\section{CONCLUSIONS}

- The Poly (diphenylamine) (PDPA) nanoparticles was synthesized by surfactant assisted dilute polymerization method and it is used for the preparation of Cu-PDPA nanocomposite coatings by simple and low temperature electrodeposition technique.

- The crystallite structure and the average grain size of the electrodeposits of copper and Cu-PDPA nanocomposites were measured by XRD analysis. The average grain size calculated by using Scherrer equation was $\sim 32 \mathrm{~nm}$ for copper and $\sim 27 \mathrm{~nm}$ for $\mathrm{Cu}$-PDPA nanocomposites and the structure was crystalline fcc for both the electrodeposits of pure $\mathrm{Cu}$ and Cu-PDPA nanocomposites.

- From the SEM analysis, the surface morphology of the Cu-PDPA nanocomposite coatings showed cauliflower like crystallites with layer by layer outward growth compared to pure copper coatings.

- The Electrochemical impedance spectroscopy (EIS) and Tafel polarization studies confirmed that the Cu-PDPA nanocomposites found to be more corrosion resistance than the electrodeposited copper coatings in $3.5 \% \mathrm{NaCl}$ solutions.

\section{REFERENCES}

1. Ramalingam, S., Balakrishnan, K., \& Subramania, A. (2015). Mechanical and corrosion resistance properties of electrodeposited $\mathrm{Cu}-\mathrm{ZrO}_{2}$ nanocomposites. Transactions of the IMF, 93(5), 262-266.

2. Tey, E., Hashim, M., \& Ismail, I. (2016). Characterization of $\mathrm{Cu}-\mathrm{Al} 2 \mathrm{O} 3$ and Ni-Al2O3 nanocomposites electrodeposited on copper substrate. In Materials Science Forum. Trans Tech Publications, 846, 471-478.

3. Ramalingam, S., Balakrishnan, K., Shanmugasamy, S., \& Subramania, A. (2017). Electrodeposition and characterisation of $\mathrm{Cu}-\mathrm{MWCNTs}$ nanocomposite coatings. Surface Engineering, 33(5), 369-374.

4. Ning, D., Zhang, A., \& Wu, H. (2019). Enhanced Wear Performance of Cu-Carbon Nanotubes Composite Coatings Prepared by Jet Electrodeposition. Materials, 12(3), 392.

5. Mandal, P., \& Mondal, S. C. (2018). Investigation of electro-thermal property of Cu-MWCNT-coated 316L stainless steel. Surface Engineering, 34(9), 697-704.

6. Ramalingam, S., Muralidharan, V. S., \& Subramania, A. (2013). Electrodeposition and characterisation of $\mathrm{Cu}-\mathrm{CeO} 2$ nanocomposite coatings. Surface Engineering, 29(7), 511-515.

7. Shanmugasamy, S., Balakrishnan, K., Subasri, A., Ramalingam, S., \& Subramania, A. (2018). Development of $\mathrm{CeO} 2$ nanorods reinforced electrodeposited nickel nanocomposite coating and its tribological and corrosion resistance properties. Journal of Rare Earths, 36(12), 1319-1325.

8. Mallikarjuna, H. M., Ramesh, C. S., Koppad, P. G., Keshavamurthy, R., \& Kashyap, K. T. (2016). Effect of carbon nanotube and silicon carbide on microstructure and dry sliding wear behavior of copper hybrid nanocomposites. Transactions of Nonferrous Metals Society of China, 26(12), 3170-3182.

9. Ramalingam, S., Muralidharan, V. S., \& Subramania, A. (2009). Electrodeposition and characterization of $\mathrm{Cu}-\mathrm{TiO} 2$ nanocomposite coatings. Journal of Solid State Electrochemistry, 13(11), 1777-1783.

10. Guo, H., Chen, Z. Q., Li, J. J., \& Li, L. (2019). Study of Fe/Ni alloy coated carbon fibres prepared by electroplating. Surface Engineering, 35(10), 841-847.

11. Lakra, S., Maharana, H. S., \& Basu, A. (2016). Synthesis and characterization of $\mathrm{Cr}-\mathrm{ZrO} 2$ composite coating formed by DC and pulse electrodeposition. Materials and Manufacturing Processes, 31(11), 1447-1453.

12. Yao, Y., Liu, Y., \& Yang, Z. (2016). A novel electrochemical sensor based on a glassy carbon electrode modified with $\mathrm{Cu}-\mathrm{MWCNT}$ 
nanocomposites for determination of hydroquinone. Analytical Methods, 8(12), 2568-2575.

13. Staia, M. H., Mejias, A., La Barbera, J. G., Puchi-Cabrera, E. S., Villalobos-Gutierrez, C., Santana, Y. Y., \& Rodriguez, M. A. (2018). Mechanical properties of WC/Co-CNT HVOF sprayed coatings. Surface Engineering, 1-9.

14. Zh,O.S., Kozlov, V.V., \& Karpacheva, G.P. (2010). Novel nanocomposite based on polydiphenylamine and $\mathrm{Cu}$ and $\mathrm{Cu} 2 \mathrm{O}$ nanoparticles. Journal of the Balkan Tribological Association, 16(3), 393-398.

15. Ozkan, S. Zh., Karpacheva, G. P., \& Kozlov, V.V. (2010). Nanocomposite based on polydiphenylamine and $\mathrm{Cu}$ :new ways for synthesis. Perspek. Mater., 9, 187-191.

16. Ozkan, S. Z., Dzidziguri, E. L., Karpacheva, G. P., \& Bondarenko, G. N. (2011). Synthesis, structure, and properties of new $\mathrm{Cu} /$ polydiphenylamine metallopolymer nanocomposites. Nanotechnologies in Russia, 6(11-12), 750-756.

17. Ramalingam, S., Subramania, A., \& Muralidharan, V.S. (2008). Preparation and Characterization of $\mathrm{Cu}$-Polyaniline nanocomposite coatings. Journal of Electrochemical Society of India, 57(1/2), 1-7.

18. Karpacheva, G., \& Ozkan, S. (2013). Polymer-metal hybrid structures based on polydiphenylamine and Co nanoparticles. Procedia Materials Science, 2, 52-59.

19. Ozkan, S. Z., Dzidziguri, E. L., Chernavskii, P. A., Karpacheva, G. P., Efimov, M. N., \& Bondarenko, G. N. (2013). Metal-polymer nanocomposites based on polydiphenylamine and cobalt nanoparticles. Nanotechnologies in Russia, 8(7-8), 452-460.

20. Showkat, A. M., Cao, X. T., Kim, D. W., Islam, M. R., \& Lim, K. T.(2015).Characterization of poly (diphenylamine)-gold nanocomposites obtained by self-assembly. In IOP Conference Series: Materials Science and Engineering, 77 (1), 012007.

21. Ozkan, S.Zh., \& Karpacheva, G. P. (2015). Synthesis, Structure and Properties of Composite Materials Based on Polydiphenylamine and Cobalt Nanoparticles. Journal of Characterization and Development of Novel Materials, 7(2), 135, 2015.

22. Ozkan, S.Zh., Karpacheva, G.P., \& Eremeev, I. S. (2016) Synthesis of the Hybrid Metal-Polymer Nanocomposite. In Physical Chemistry for the Chemical and Biochemical Sciences, Apple Academic Press, 2016, pp. $141-151$.

23. Tsai, Y. T., Wen, T. C., \& Gopalan, A. (2003). Tuning the optical sensing of $\mathrm{pH}$ by poly (diphenylamine). Sensors and Actuators B: Chemical, 96(3), 646-657.

24. Orlov, A. V., Ozkan, S. Z., Bondarenko, G. N., \& Karpacheva, G. P. (2006). Oxidative polymerization of diphenylamine: synthesis and structure of polymers. Polymer Science Series B, 48(1), 5-10.

25. Ozkan, S. Z., Karpacheva, G. P., Orlov, A. V., \& Dzyubina, M. A. (2007). Thermal stability of polydiphenylamine synthesized through oxidative polymerization of diphenylamine. Polymer Science Series B, 49(1-2), $36-41$.

\section{AUTHORS PROFILE}

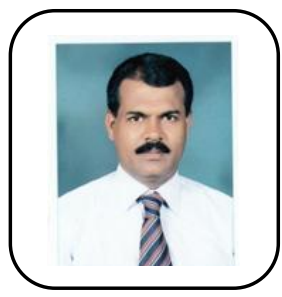

Dr. S. Ramalingam obtained his M.Sc., M.Phil. \& Ph.D. degree from Department of Industrial Chemistry, Alagappa University, Karaikudi-630 003, Tamil Nadu, India. Presently, he is working as Assistant Professor in the Department of Chemistry, School of Advanced Sciences (SAS), Kalasalingam Academy of Research and Education (Deemed to be University), Krishnankoil-626 126, Tamil Nadu, India. He has 12 years of Teaching and Research Experience and 8 years of Industrial experience. His research areas of interest are Electrodeposition \& Corrosion and Nanomaterials Chemistry and published several articles in reputed international / national journals. He is a Fellow Life member in the Society for Advancement of Electrochemical Science \& Technology (SAEST), CECRI, Karaikudi-630 003, Tamil Nadu, India and Life member in Association of Chemistry Teachers (ACT), TIFR, Mumbai-400 007, India. 